\title{
Real ileal digestibility of sunflower protein and amino acids in humans
}

\section{Abstract}

Introduction:

Sunflower protein is not used in human nutrition despite a relatively good amino acid composition. However, the bioavailability of sunflower isolate has never been measured in Humans. The goal of this work was to determine ileal digestibility of protein and amino acids from a sunflower isolate in healthy volunteers and to challenge newly developed dual isotope method.

\section{Materials and methods:}

Eight healthy volunteers were equipped with a naso-ileal tube. They received during four hours twelve doses of biscuits containing, in total, $25 \mathrm{~g}$ of ${ }^{15} \mathrm{~N}$ sunflower protein isolate together with $400 \mathrm{mg}$ of a mixture of free ${ }^{13} \mathrm{C}$ amino acids incorporated in chocolates. Polyethylene glycol was perfused as non-absorbable marker and ileal contents were collected during 8 hours after ingestion of the first meal. Real ileal digestibility was measured by assessing nitrogen and carbon content as well as ${ }^{15} \mathrm{~N}$ and ${ }^{13} \mathrm{C}$ enrichments by EA-IRMS. Amino acid digestibility was determined by measuring ${ }^{15} \mathrm{~N}$ and ${ }^{13} \mathrm{C}$ enrichments by GC-C-IRMS and quantity of amino acids by UPLC. Blood was collected for $8 \mathrm{~h}$ to determine ${ }^{15} \mathrm{~N}$ and ${ }^{13} \mathrm{C}$ enrichments by GC-C-IRMS.

\section{Results:}

The ileal nitrogen flow was $2.7 \pm 0.5 \mathrm{~mL} / \mathrm{min}$ (mean $\pm \mathrm{SD}$ ). In average, $53.1 \pm 12.0 \mathrm{mmol}$ of exogenous nitrogen was recovered during the eight hours of experiment, resulting in an ileal digestibility of sunflower isolate was $85.6 \pm 2.6 \%$ of nitrogen ingested. ${ }^{13} \mathrm{C}$ amino acids were also recovered at the ileal level. The mixture of free ${ }^{13} \mathrm{C}$ revealed an ileal digestibility of $94.9 \pm 0.9 \%$. Ileal indispensable amino acids digestibility and DIAAS are in progress.

\section{Discussion:}

Ileal digestibility of sunflower isolate incorporated in toasted biscuits was lower than the value found or a raw isolate in a rat model $(94.5 \%)$. The study revealed that $5 \%$ of free amino acids were not absorbed in the ileum. Amino acid digestibility will complete the study to evaluate the DIAAS of sunflower isolate and to compare values obtained with the standard method and with the dual isotope method.

\section{Conflict of Interest}

There is no conflict of interest. 